\title{
Love the root, not the flowers everyone sees
}

\author{
Tomasz A. Timek, MD, PhD
}

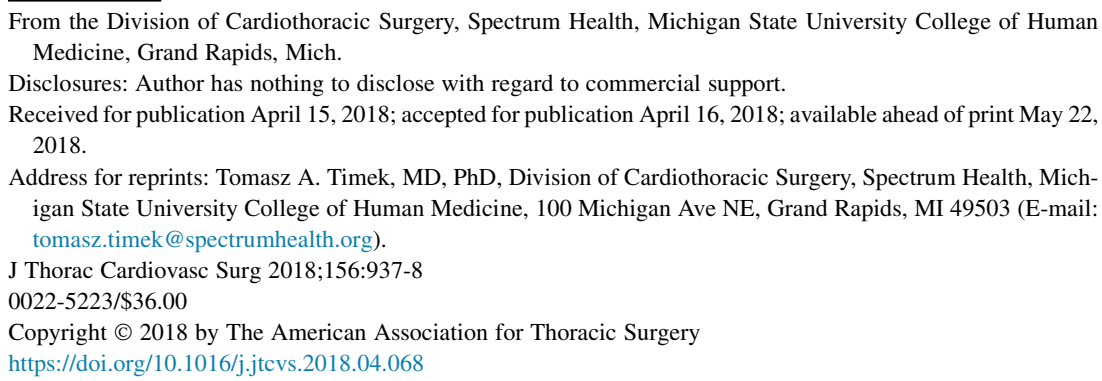

From the Division of Cardiothoracic Surgery, Spectrum Health, Michigan State University College of Human Medicine, Grand Rapids, Mich.

Disclosures: Author has nothing to disclose with regard to commercial support.

Received for publication April 15, 2018; accepted for publication April 16, 2018; available ahead of print May 22, 2018.

Address for reprints: Tomasz A. Timek, MD, PhD, Division of Cardiothoracic Surgery, Spectrum Health, Michigan State University College of Human Medicine, 100 Michigan Ave NE, Grand Rapids, MI 49503 (E-mail: tomasz.timek@spectrumhealth.org).

J Thorac Cardiovasc Surg 2018;156:937-8 $0022-5223 / \$ 36.00$

Copyright (C) 2018 by The American Association for Thoracic Surgery https://doi.org/10.1016/j.jtcvs.2018.04.068

The aortic root is a complex, 3-dimensional structure with heterogeneous behavior during the cardiac cycle. ${ }^{1}$ The intricate dynamic geometry of the aortic root is thought to minimize leaflet stresses and transvalvular turbulence, leading to optimal hemodynamic profile and durability. Perturbations of normal root dynamics may lead to abnormally high leaflet stresses and premature structural valve deterioration. Whether valve-sparing procedures mimic the dynamic geometry of the native aortic root remains unclear, but the hemodynamic and flow profile of valve-sparing root procedures, as derived from in vivo time-resolved 3dimensional magnetic resonance phase-contrast imaging, was recently found to be superior to that of bioprosthetic valved conduit replacement. ${ }^{2}$ Addition of a sinus-shaped aortic graft prosthesis may confer further physiologic advantage. ${ }^{3}$ In this issue of the Journal, Yacoub and colleagues ${ }^{4}$ add further insight into the dynamic behavior of the aortic root after the root remodeling procedure. With phase-contrast cardiac magnetic resonance and computed tomographic angiography and computational flow dynamics, Yacoub and colleagues ${ }^{4}$ studied 2 young patients who underwent the root remodeling procedure and 4 agematched control subjects. The remodeling operation was associated with nearly normal aortic root dynamic geometry and flow patterns in the ascending aorta and sinuses of Valsalva. These findings add support to the "physiologic" repair of aortic root aneurysms that has been championed by Yacoub for more than 4 decades. The current report of Yacoub and colleagues ${ }^{4}$ must be interpreted in the appropriate context, however, especially because both presented patients were young women of small body habitus. It is unknown whether these findings are generalizable to the greater cardiac population, because the aortic root and ascending aorta complex is disproportionately small in young patients, particularly women. The mean age of patients undergoing a valve-sparing root operation was reported in a recent comprehensive summary at $51 \pm 14.7$ years, ${ }^{5}$ and, because age-related changes to aortic stiffness alter human ascending aortic hemodynamics derived by computational modeling, ${ }^{6}$ the extrapolation of

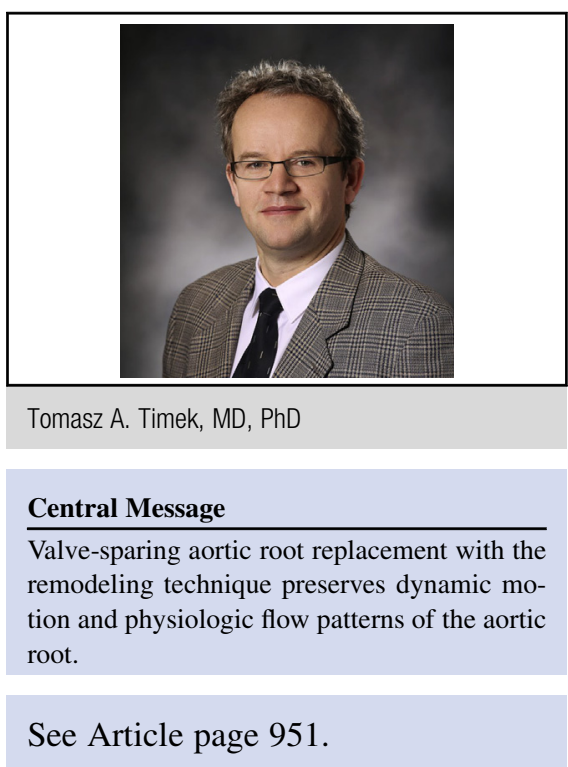

the current finding to older patients remains to be established. The 2 study patients had the same body surface area $\left(1.8 \mathrm{~m}^{2}\right)$; however, annular area was almost double in patient 2 (Figure 4 in the article of Yacoub and colleagues ${ }^{4}$ ), and postoperative annular diameter was approximately $35 \mathrm{~mm}$ (Figure 8 in the article of Yacoub and colleagues ${ }^{4}$ ). These anatomic features were associated with less complete leaflet coaptation after the procedure (Figure 2, $B$, in the article of Yacoub and colleagues ${ }^{4}$ ), with a residual regurgitation of $9.3 \%$. Without an annular stabilizing or reducing procedure, the durability of the remodeling surgery may not be equivalent in these 2 patients, because an aortoventricular junction diameter of $28 \mathrm{~mm}$ or greater has been shown in a large patient cohort to be an independent predictor of reoperation for root remodeling. ${ }^{7}$ Maintained dynamic motion of the large annulus in patient 2, although physiologic, may contribute to further dilation and increased aortic insufficiency; as such, preservation of "normal" annular dynamics may not always be advantageous. Annular stabilization has been identified as a potential advantage of the root reimplantation technique, although leaflet dynamics, as elegantly demonstrated in the current report of Yacoub and colleagues, ${ }^{4}$ have been purported to be more physiologic with the remodeling procedure. 9,10 Torsion is an important component of the aortic root deformation that "winds" and "unwinds" throughout the cardiac cycle to facilitate ejection and aortic flow ${ }^{1}$ yet was not investigated in the study. Although the graft prosthesis may limit this evaluation, data from control subjects 
may better elucidate the optimal material properties of graft prostheses to normalize torsional deformation.

Harnessing advanced imaging and computational techniques, Yacoub and colleagues ${ }^{4}$ have provided us with a unique glimpse into detailed dynamic physiology of the aortic root after the root remodeling procedure. Multimodal imaging promises to enhance our understanding of the 3dimensional geometry and flow patterns of the aortic root and potentially guide surgical repair to optimize leaflet stresses and yield improved durability. Much work remains to better characterize the heterogeneity of human aortic root pathology, but studies such as that of Yacoub and colleagues ${ }^{4}$ will continue to reveal the complex wonder of the aortic root.

\section{References}

1. Dagum P, Green GR, Nistal FJ, Daughters GT, Timek TA, Foppiano LE, et al Deformational dynamics of the aortic root: modes and physiologic determinants. Circulation. 1999;100(19 Suppl):II54-62.

2. Collins JD, Semaan E, Barker A, McCarthy PM, Carr JC, Markl M, et al. Comparison of hemodynamics after aortic root replacement using valve-sparing or bioprosthetic valved conduit. Ann Thorac Surg. 2015;100:1556-62.
3. Ochtering TH, Hons CF, Sieren M, Hunold P, Hennemuth A, Huellebrand M, et al. Time-resolved 3-dimensional magnetic resonance phase contrast imaging (4D Flow MRI) analysis of hemodynamics in valve-sparing aortic root repair with an anatomically shaped sinus prosthesis. J Thorac Cardiovasc Surg. 2016;152:418-27.e1

4. Yacoub M, Aguib H, Gamrah MA, Shehata N, Nagy M, Donia M, et al. Aortic root dynamism, geometry, and function after the remodeling operation, clinical relevance. J Thorac Cardiovasc Surg. 2018;156:951-62.e2.

5. Arabkhani B, Mookhoek A, Di Centa I, Lansac E, Bekkers JA, De Lind Van Wijngaarden $\mathrm{R}$, et al. Reported outcome after valve-sparing aortic root replacement for aortic root aneurysm: a systematic review and meta-analysis. Ann Thorac Surg. 2015;100:1126-31.

6. Cuomo F, Roccabianca S, Dillon-Murphy D, Xiao N, Humphrey JD, Figueroa CA. Effects of age-associated regional changes in aortic stiffness on human hemodynamics revealed by computational modeling. PLoS One. 2017;12: e0 0173177 .

7. Schäfers HJ, Raddatz A, Schmied W, Takahashi H, Miura Y, Kunihara T, et al. Reexamining remodeling. J Thorac Cardiovasc Surg. 2015;149(2 Suppl): S30-6.

8. David TE, Feindel CM, Webb GD, Colman JM, Armstrong S, Maganti M. Longterm results of aortic valve-sparing operations for aortic root aneurysm. J Thorac Cardiovasc Surg. 2006;132:347-54

9. Leyh RG, Schmidtke C, Sievers HH, Yacoub MH. Opening and closing characteristics of the aortic valve after different types of valve-preserving surgery. Circulation. 1999;100:2153-60.

10. Graeter TP, Fries R, Aicher D, Reul H, Schmitz C, Schäfers HJ. In-vitro comparison of aortic valve hemodynamics between aortic root remodeling and aortic valve reimplantation. J Heart Valve Dis. 2006;15:329-35. 